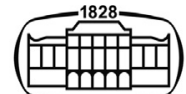

AKADÉMIAI KIADÓ

Pollack Periodica •

An International Journal

for Engineering and Information Sciences

$16(2021) 3,169-174$

DOI:

$10.1556 / 606.2021 .00334$

(c) 2021 The Author(s)

\title{
Application of environmental psychology in kindergarten architectural design
}

\author{
Hui Cao ${ }^{1,2 *} \oplus$, Anna Mária Tamás ${ }^{3}$ and Gergely Sztranyák ${ }^{4}$
}

\author{
${ }^{1}$ Marcel Breuer Doctoral School, Faculty of Engineering and Information Technology, University of \\ Pécs, Boszorkány u. 2, H-7624 Pécs, Hungary \\ ${ }^{2}$ Department of Fine Arts Environmental Design Teaching and Research Office, Jinzhong University, \\ Jinzhong, China \\ ${ }^{3}$ Department of Architecture and Urban Planning, Faculty of Engineering and Information \\ Technology, University of Pécs, Boszorkány u. 2, H-7624 Pécs, Hungary \\ ${ }^{4}$ Department of Building Structure and Energy Design, Faculty of Engineering and Information \\ Technology, University of Pécs, Boszorkány u. 2, H-7624 Pécs, Hungary
}

Received: December 29, 2020 • Revised manuscript received: March 9, 2021 • Accepted: March 21, 2021 Published online: April 20, 2021

\section{ORIGINAL RESEARCH PAPER}

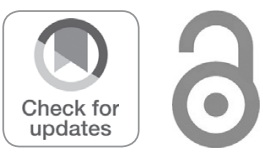

\begin{abstract}
With the reform of China's childbirth policy in recent years, a unique baby boom phenomenon has emerged, and the new-born baby has increased rapidly in China. In the process of transformation and development of contemporary cities, a complex urban environment has a significant impact on psychology and physiology. The past kindergarten architectural aesthetic experience can no longer adapt to the social development needs. Thus, how to realize the sustainable development of kindergarten architecture has become a social problem that needs to be solved urgently. In the context of Environmental Psychology, this paper investigates the construction mode of experiential kindergarten architecture and tries to explore a new paradigm of educational architecture design in China for the future.
\end{abstract}

\section{KEYWORDS}

kindergarten, environmental psychology, interactive experience, sustainability, space atmosphere

\section{INTRODUCTION}

As the material carrier of early childhood education, kindergarten plays a significant role in modern cities. In essence, kindergarten is a "space for children's life, growth, and entertainment". It is a comprehensive place for young children to develop cognitive, emotional, social connections and individual skills [1]. Kindergarten reflects the complicated relationship between the individual and collective of children in emotional cognition and social perception, and infant space plays an extremely crucial role in their growth development. According to statistics, the consumption of infants and young children in China accounts for $18-30 \%$ of the total household consumption, among which the investment in early childhood education occupies the primary position [2]. With the advancement of urbanization, the renewal and development of kindergarten have become a significant issue. City expectations for kindergartens have soared as well. However, most of the functional design in kindergartens does not meet the needs of children's physical and mental development in current times, and there is little interaction between children and the environment, especially lack of experience and system design.

School is not only a place to impart book knowledge but also a place to impart survival skills and the art of life [3]. Based on the correlation between environmental design and children's healthy growth, a high-quality space design pattern can bring a healthy, comfortable, and pleasant living experience to preschool children. In the ways in which an 
orderly environment is interpreted as an orderly state of mind [4], try to realize the sustainable development of physical space and people. Therefore, to achieve a happy growth experience, architects and educators should start from the context of Environmental Psychology to create a space atmosphere that is in line with the physical and mental development characteristics of contemporary children groups through cross-border cooperation. In this paper, the author takes Jinzhong No. 1 (J1) kindergarten as the research object and bases it on Environmental Psychology and architecture to deal with the complex problems between society and the kindergarten. Try to construct a positive space experience and form a diversified space paradigm to meet the future.

\subsection{Project introduction}

Jinzhong No. 1 kindergarten is located in Yuci District, Jinzhong City, China, founded in 1950; it is the first provincial-level demonstration kindergarten directly under Jinzhong City. The park covers an area of 17.35 acres, with a construction area of 11,924 square meters. At present, with the deepening of China's preschool education reform and the updating of educational concepts, the original educational environment and the interpretation of the current concepts have become estranged. A more inclusive built environment will have a positive impact on preschool education. Therefore, to improve the social image and realize the sustainable development of the educational environment, Jinzhong Municipal Government began to upgrade and renovate the old building based on the existing construction conditions in early 2020. The author and his research team worked closely with Jinzhong No.1 kindergarten on this project.

\subsection{Design objects}

This project mainly involves the renovation and upgrading of the existing buildings. Taking the concept of social innovation design as the core driving force and based on the interdisciplinary approach, the author puts forward the design paradigm of experiential education architecture. The author takes the renewal of kindergarten buildings as an example to analyze the cross-border integration between architectural design and environmental psychology. The project consists of four parts, the entrance building, the central event plaza, the pet park area, and the backyard garden. The author chooses the renewal of the entrance building as the object to carry out analysis and study.

\section{MATERIALS AND METHODS}

\subsection{Research materials}

Environmental psychology is an applied discipline that studies the connection between human behavior and the environment [5]. It emphasizes the interaction between human and their environment. As a study field, it seeks to understand how and why the environment affects people's lives, how to use it to human advantage, and what to do to improve human relationships with the world around. It focuses on the human aspects of environmental problems and the ways to solve them as well. The author believes that with the increasing complexity of the urban environment and social issues, combining environmental psychology with architecture is an effective way to deal with this complicated situation.

Kindergarten architectural space refers to the physical environment created to serve kindergarten education. The modeling factors of design mainly include physical form, spatial organization, color composition, and other aspects. Without a doubt, the analysis of the building type of kindergarten not only relates to the feelings brought by itself but also the multi-faceted needs of uses and recipients for the building functions [6]. Generally, kindergarten architectural design is including modeling, empathy, convey [7]. On the one hand, it shows how the environment affects children's behaviors; and on the other hand, how the infants affect their surrounding environment. The process reflects the interrelationship between people and the physical environment, which is consistent with the relevant field of Environmental Psychology research.

\subsection{Methods}

In this study, the author proposed an interdisciplinary research method, combining the relevant theories of environmental psychology with architectural design, to conduct design practice research on the architectural design of local community kindergartens in China.

At first, the author starts with an extensive literature review, the successful concrete cases and relevant studies are analyzed. Secondly, the author and his team conducted a targeted urban survey in Chinese cities and used the method of mapping to collect the research image data, record the children's behavior, to make a qualitative analysis of the current situation of the community kindergarten building. Then the author applied the participatory action research method to the field survey and discussion of community kindergartens and obtained a large number of valuable data through the statistics of the questionnaire survey. Besides, cross-border collaboration with the stakeholders, educational institutions, and urban authorities is a breakthrough in this study. Finally, based on the preliminary comprehensive research, the design concept of experiential architecture is proposed, and the author summarized the perceptive object system of kindergarten experiential architecture. Finally, based on the previous research, the author puts forward the core elements of experiential architectural design.

2.2.1. Analysis of urban surveys. Based on Reid Ewing's urban design quality theory [8], the author has carried out an urban survey about the community kindergarten and proposed an evaluation method for architectural design quality, including the recognizability, atmosphere, environmental scale, esthetic character, and synthesis value. The 


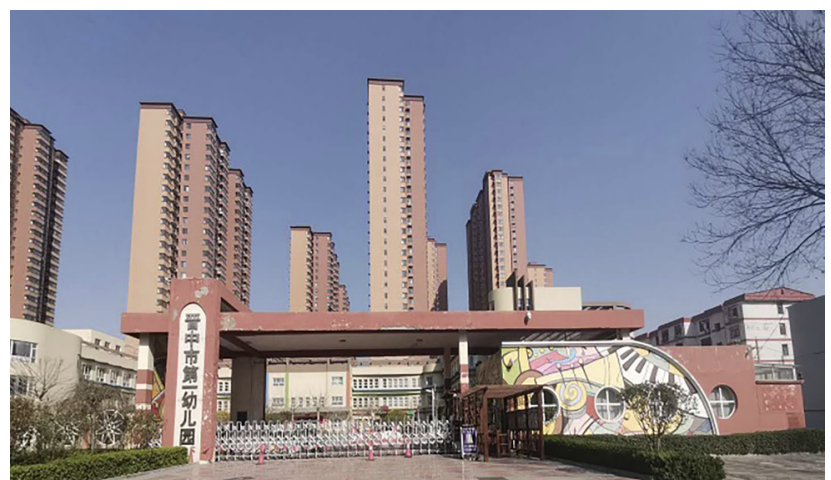

Fig. 1. Status quo of J1 kindergarten (Source: Photographed by H. Cao)

author also carried out the image data collection, behavior record, and analysis for J1 kindergarten and other targets to provide foundational data for the project implementation. In Figs 1 and 2, the investigation and analysis of the current situation of J1 kindergarten are as follows (Figs 1 and 2):

A. Recognizability. All the respondents have common spatial characteristics and identifiability in their communities and the architectural form tends to be more democratic. The space composition of the kindergarten and the entrance is relatively single, and the degree of integration with the surrounding environment is not ideal, so it cannot form high-quality visual visibility to the public. The facade communication design of architecture lacks positive social perception and identification;

B. Atmosphere. The application form of decoration material and colors is relatively simple, and the construction craft is rough and even the connection between all sorts of material is not beautiful. So that the formation of directional thinking and inertial design errors. Most kindergarten buildings are more direct in the expression of space atmosphere, and the relationship between environment and children only stays in the use of the fundamental functions of physical space, without

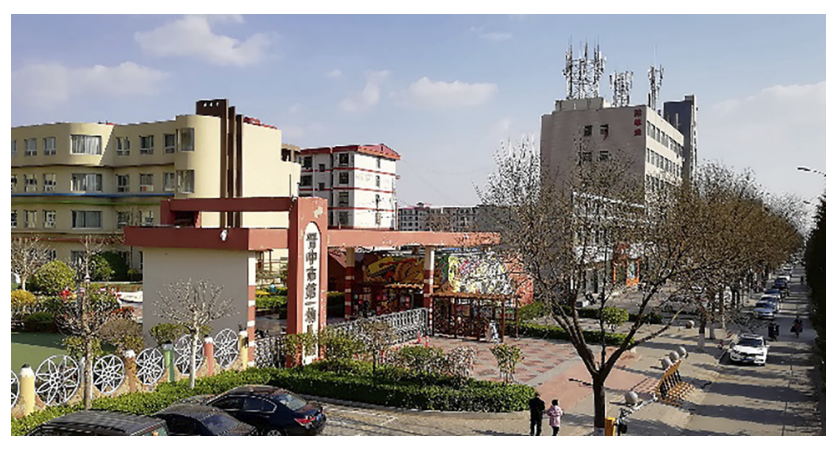

Fig. 2. Status quo of J1 kindergarten (Source: Photographed by H. Cao) forming emotional dialog and positive interactive experience;

C. Environmental scale. The relationship between architectural decoration and children's scale is fuzzy, especially in some design elements of public space that do not meet the requirements of children's ergonomics. Through field research, it is mainly reflecting in the large scale of the architectural elements. In particular, the connection between the building and the surrounding environment is relatively rigid, and the insufficient consideration of children's environmental perception and spatial cognition, and other factors in the landscape configuration. It could not create a child-friendly environment;

D. Esthetic character. As the general visual form of kindergarten decoration elements, the symbolic cartoon image has poor timeliness and symbolism, which is easy to cause esthetic fatigue and form low-grade emotional expression. Due to the lack of multiple concerns of humanistic esthetics and artistic esthetics, the systematic design has not constituted by building form, space composition, design elements, color collocation, and other aspects, and esthetic perception of art needs to be improving;

E. Synthesis value. The respondents failed to convey a clear value orientation, with single cultural connotations and limited social values reflected in the community. On the other hand, the compatibility of environmental space is insufficient. Most kindergarten designs fail to take into account the importance of design factors such as complexity and sociality.

2.2.2. Analysis of participatory action research. In the preliminary investigation, the author conducted a participatory action research method. The team selected a total of 60 urban residents for this questionnaire survey. Participants included: children, teachers, community residents, parents, and education experts. The public has chosen the five aspects of the kindergarten building that most need improvement. The five items with the highest selection ratio contain interactive design, styling features, visual and sound design, emotion design, cultural connotation. These results will support specific design practices.

\section{RESULTS AND DISCUSSION}

How to create a new paradigm of architecture design is the principal goal of this study. Architects needed to create a physical space based on a child-friendly design perspective. It is not only necessary to create a better visual effect for children, but more importantly to stimulate them to produce positive emotions. The social environment and social interactions are important when it comes to children's learning [9]. Therefore, the author puts forward the experience-oriented kindergarten design strategy and conducts two-way research on the relationship between early childhood education and the built environment. 


\subsection{Design strategy of experiential kindergarten}

Experiential kindergarten architecture is a kind of childcentered space that emphasizes the sensory experience of architecture, especially the significant role of physical space in stimulating children's visual, tactile and auditory responses. Essentially, participation and emotional experience are the basis of design, and the interaction between infants and physical space is the design approach. Through the creation of space, create a healthy atmosphere for individuals so that could easily immerse themselves. This process reflects the cooperation and information exchange between the architects and the users of the space.

Creating a space atmosphere, people-oriented, and the interaction between people and space are the core contents of experiential architectural study. The sense of belonging of the environment space is the goal of the design. It reflects the procedure of physical space developing and responding with time. Meanwhile, the sense of belonging to the environment stimulates the formation of children's spatial memory, which reflects the concept of the overall design of educational buildings. The author summarizes the perceptive object system of kindergarten experiential architecture to guide the specific design practice (Table 1), including visual elements, other elements, perception elements, and cognitive elements, which embodies the systematic thinking on the architectural design.

\subsection{Case discussion}

The planning phase is one of the most critical phases in realizing a building [10]. Under the background of environmental psychology, the author systematically updated the entrance building of J1 kindergarten according to the current situation. The creation of architecture space links with the perceptive object system and following the four aspects: architectural spatial pattern, children's physical and mental needs, cognitive processing, and kid's behavior characteristics. The project group undertook the concrete experiment to support the hypothesis of experiential architecture.

First and foremost, the design starts from the renewal of architectural spatial patterns based on the old entrance building. Under the problem-oriented design approach, it is a new attempt to respond to the current needs of global epidemic prevention and control with scientific spatial planning strategies. According to the technical plans for epidemic prevention and control in childcare institutions [11], the design team systematically planned and adjusted the existing layout to enhance the building's comprehensive functionality. For example, we reprogrammed the approach route; some unique functional areas in line with epidemic control have been designed, including the observation room, isolation area, disinfection room, medical room, and other spaces. The more effective connection between the functional area ensures the rationality of the design and enriches the spatial composition of the building (Fig. 3). Furthermore, high-quality steel structures and various aluminum processes are used as new construction approaches, emphasizing the building's functionality, timeliness, and safety.

There is one more point, through the principle of peopleoriented design, a positive visual perception process is created based on the physical and mental needs of the infants, with a unique emphasis on color design and sight control. The color of architecture plays an irreplaceable role in inspiring imagination. According to the characteristics of kid's perception, the author chose white, yellow, coffee, and

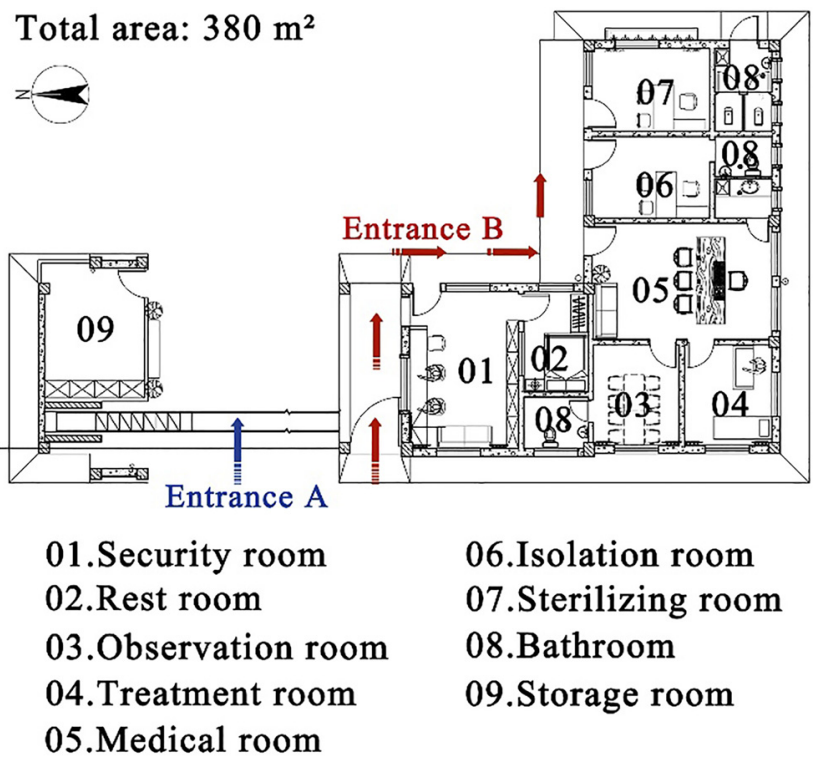

Fig. 3. Functional plan of the entrance building (Source: Designed by H. Cao )

Table 1. The perceptive object system of kindergarten experiential architecture

\begin{tabular}{lccc}
\hline \multicolumn{2}{l}{ The perceptive object system of kindergarten experiential architecture } & & \\
\hline Visual elements & Other elements & Perception elements & Cognitive elements \\
Styling features & Shade control & Unique appearance & Physical needs \\
Color features & Fire design & Harmonious color & Mental needs \\
Material elements & Visual design & Proper scale & Emotional Needs \\
Landscape features & Touch design & Space atmosphere & Experience \\
Greening design & Insulation design & Esthetic demand & Spatial innovation \\
Recognizability & Emotion design & Natural harmony & Children's behavior \\
Symbolic features & Interactive design & Life force & Communication \\
\hline
\end{tabular}


purple as the decorative colors. These hues play different personality characteristics, which could arouse an individual emotional response. Also, the author sets a particular design on the relationship between the visual organization and architecture through the anchoring effect [12] by translating desirable feelings into architectural concepts [13] and forming belonging in space. The architectural form is graphically processed and endowed with symbolic features, which provides a specific anchor point for people's sight, also promotes the correlation between individual visual movement and spatial organization (Fig. 4).

In the third place, redesign the relationship between environment and children according to emotional needs and cognitive processing, endowing buildings with unique emotional connotations and creating an architectural space paradigm suitable for children. The concept of architecture facade inspired by the Tangram, which is a traditional Chinese puzzle and the overall modeling mainly includes three different design expressions. For instance, the shape of the west side of the building, which faces the community, takes design elements from an abstract variation of the English words "Man" and "Woman" to represent hope and vitality. On the east side, the building faces the inner area, inspired by the famous Chinese cartoon character Tuan Zi. The empathic power generated by the space could bring a child-friendly feeling of experience. On the north side, the building faces the public part, where is inspired by the image of Garfield. Due to the rich content of symbols, the extraordinary contemporary architectural form was resulted [14], the bionic forms of this design method create a strong sense of spatial involvement and enrich the emotional needs of children (Fig. 5).

Last but not least, based on children's behavioral characteristics, the active interaction between kindergarten and

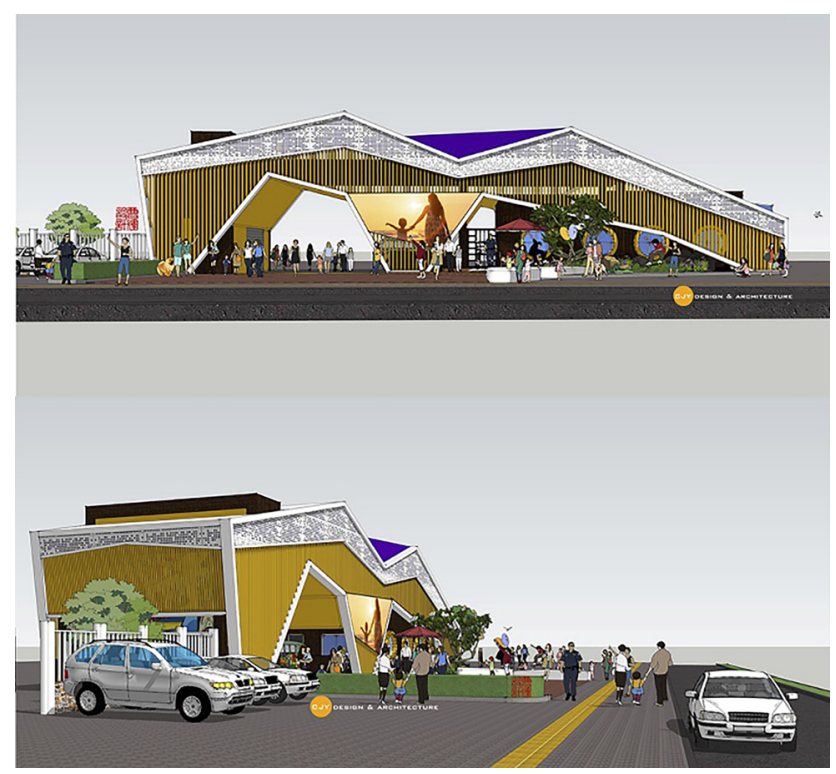

Fig. 4. Color analysis and visual control of the building (Source: Designed by H. Cao) society is formed through the construction of physical space, to improve the degree of interactive experience between crowds and space. The main starting point in early childhood education is both to view children as active agents and stakeholders for the future and to ensure their involvement [15]. In this part, the author enhanced the path planning of the entrance area, which formed multiple communication possibilities in the process of entering the kindergarten (Fig. 6). For example, streets share rest facilities and landscape for the community and the kids who lived; digital multimedia interactive devices have been added to the building surface to enable the public to obtain more information about early childhood education; exhibition space for children's artworks below the building for good communication. Through path planning reasonably, the orderly connection of multiple space nodes can be formed to create a stronger sense of atmosphere and formed positive social relations (Fig. 7).

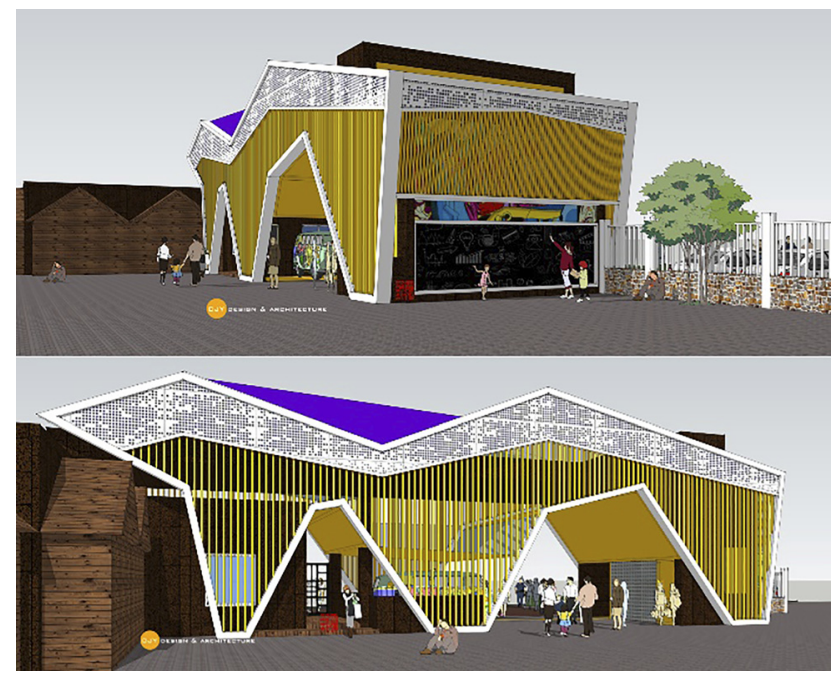

Fig. 5. Design inspiration analysis diagram (Source: Designed by H. Cao)

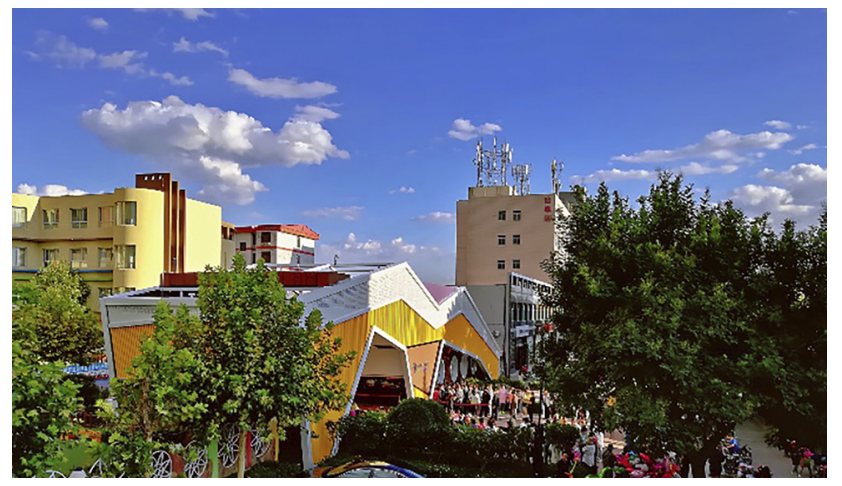

Fig. 6. The facade of the building after completion (Source: Photographed and designed by H. Cao) 


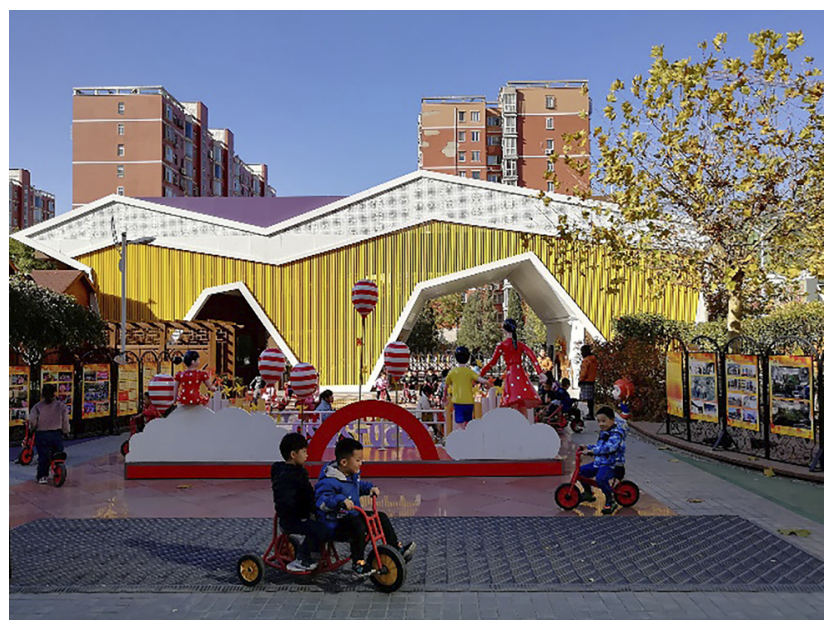

Fig. 7. The back facade of the building after completion (Source: Photographed and designed by H. Cao)

\section{CONCLUSION}

Architecture should be endowed with more humanistic factors to establish a sustainable development paradigm between humans and the environment and create more possibilities for activities. Each building has vitality, continuously grows in its specific environment, and has a subtle relationship with the surroundings. A high-quality environment stimulates people's creativity, and people will also give play to their subjective initiative to carry out outstanding cooperation with the environment. The interaction between architecture and kids makes the physical space have an emotional sense of temperature. Architects should use design elements to stimulate the emotional connection between the environment and kids intelligently and then make full use of the environment to enhance the child's subjective initiative.

The paradigm of experiential architecture reflects the active involvement of environmental psychology in environmental construction. Experiential architecture is full of exploration of the possibility for future architectural design. It also restructures the process of perception and cognition and creates positive experiences for people. From the author's perspective, the design needs to base on security, functionality, experiential, creativity, and sociality, which not only embodies the particularity of contemporary architecture as the carrier of children's education but also reflects the spiritual quality of architectural design. This design practice will become an effective way to evaluate the architectural environment design of kindergartens and form a new paradigm in the future.

\section{ACKNOWLEDGEMENTS}

The author would like to thank Jinzhong No.1 Kindergarten, for the kind invitation that allows the author to take charge of this project. The author gratefully acknowledges the Jinzhong municipal government for their support of the project. The author gratefully acknowledges the support of Marcel Breuer Doctoral School, University of Pécs. Besides, the author is grateful to the editors and reviewers for their constructive comments on this paper.

\section{REFERENCES}

[1] J. H. Wu, "Kindergarten architectural design space - study on children's space”, Building Struct., vol. 50, no. 9, pp. 159-159 (in Chinese), 2020.

[2] G. Y. Qian, Y. Du, and S. J. Yang, "The application of infants physiological and psychological development characteristics in the design of educational toys", Packaging Eng., vol. 41, no. 10, pp. 37-41 (in Chinese), 2020.

[3] A. Alfred and T. T. Wang, The Education of Children. Beijing: China Industry and Commerce Joint Press (in Chinese), 2017.

[4] A. M. Besson, "Aesthetics and affordances in a favorite place: on the interactional use of environments for restoration", Environ. Values, vol. 29, no. 5, pp. 557-577, 2020.

[5] L. Q. Xu and G. X. Yang, Environmental Psychology. Shanghai: Tongji University Press (in Chinese), 2019.

[6] L. J. Luo, "Application of architectural semiotics in kindergarten architectural design", Chongqing Archit., vol. 15, no. 155, pp. 8-10 (in Chinese), 2016.

[7] Y. F. Wen, "Architectural semiotics and prototype thinking", Archit. J., vol. 59, no. 5, pp. 87-92 (in Chinese), 2012.

[8] R. Ewing and S. Handy, "Measuring the unmeasurable: urban design qualities related to walkability", J. Urban Des., vol. 14, no. 1, pp. 65-84, 2009.

[9] B. Farhana, "A case study of a green flag-certified preschool in Sweden”, Hungarian Educ. Res. J., vol. 9, no. 4, pp. 607-627, 2019.

[10] K. R. Horváth and I. Kistelegdi, "Award winning first Hungarian active house refurbishment”, Pollack Period., vol. 15, no. 2, pp. 233-244, 2020.

[11] Ministry of Education of the People's Republic of China, The Ministry of Education and the National Health Commission issued technical plans for epidemic prevention and control in primary and secondary schools and childcare institutions, 2020. [Online]. Available: http://www.moe.gov.cn/. Accessed: Oct. 17, 2020.

[12] W. C. Zhang, Murphy's Law. Suzhou: Guwuxuan Publishing House (in Chinese), 2019.

[13] How architects create emotional connections: Experimental designs by three raise the bar, 2020. [Online]. Available: https://csengineermag. com/how-architects-create-emotional-connections-experientialdesigns-by-three-raise-the-bar/. Accessed: Dec. 15, 2020.

[14] Q. Zhang and A. Hutter, "From traditional symbol to new contemporary form”, Pollack Period, vol. 14, no. 3, pp. 3-10, 2019.

[15] E. B. Hacking, R. Barratt, and W. Scott, "Engaging children: research issues around participation and environmental learning", Environ. Edu. Res., vol. 13, no. 4, pp. 529-544, 2007. 